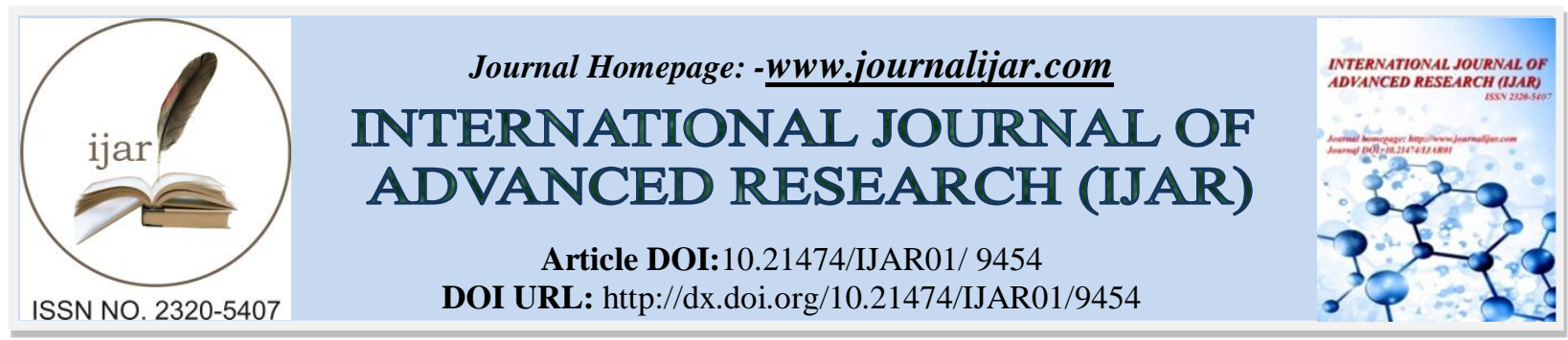

RESEARCH ARTICLE

\title{
ASSESSMENT OF THE RELATIONSHIP BETWEEN THE MONITORING RESULTS OF PATIENTS WITH VIRAL HEPATITIS-RELATED HEPATOCELLULAR CARCINOMA AND TYPE 2 DIABETES MELLITUS.
}

\author{
Yasin Ozturk ${ }^{1}$, Guray Ceylan ${ }^{2}$, Coskun Sokmen ${ }^{3}$ and Muammer Bilici ${ }^{1}$. \\ 1. Department of Internal Medicine, ZBEU, Turkey. \\ 2. Department of Internal Medicine, Denizli Government Hospital, Turkey. \\ 3. Dr. Abdurrahman Yurtaslan Oncology Training and Research Hospital, Turkey.
}

\section{Manuscript Info}

……………

Manuscript History

Received: 24 May 2019

Final Accepted: 26 June 2019

Published: July 2019

Key words:-

Chronic hepatitis B, chronic hepatitis C, hepatocellular carcinoma.

\section{Abstract}

Background: Among the etiological factors of hepatocellular carcinoma (HCC), which is the most frequently encountered cause of primary liver cancers, viral hepatitis cases are at the top. The relationship between glucose anomalies and HCC development in especially patients with viral hepatitis $\mathrm{C}$ and $\mathrm{B}$ infections is still a topic of curiosity. In this study, we aimed to assess the potential relationship between the chronic hepatitis $\mathrm{C}$ and $\mathrm{B}$ infections (HBV and HCV) in monitoring of HCC patients and type 2 diabetes mellitus (DM) comorbidity.

Material and Method: A total of consecutive $51 \mathrm{HCC}$ patients with a mean age of $69.98 \pm 11.92$ years were enrolled in this study. The Barcelona-Clinic Liver Cancer (BCLC) criteria were used for staging the patients with HCC. HBsAg seroprevalence with the Anti-HCV antibody was studied with the ELISA method. The patients were grouped based on presence of diabetes, and the relationships between disease stages and viral etiological factors were statistically analyzed.

Results: In patients with HCC, DM prevalence was $41.2 \%$. 55.6\% of Chronic hepatitis $\mathrm{C}$ patients and only $33.3 \%$ of chronic hepatitis B patients had diagnoses of DM ( $\mathrm{p}=0.107)$. According to the BCLC stages in the patients, the DM rates at A, B, and C were $40 \%, 45.5 \%$ and $50 \%$ respectively $(\mathrm{p}<0.05)$.

Conclusion: Blood sugar regulation in chronic viral hepatitis patients with DM may contribute to reduction of HCC risk.

Copy Right, IJAR, 2019,. All rights reserved.

\section{Introduction:-}

Chronic viral hepatitis is a problem that threatens public health which is seen commonly worldwide. Acute hepatitis B (HBV) and C (HCV) infections experienced in adulthood become chronic by $5-10 \%$ and $75-85 \%$ respectively. Also, cirrhosis and hepatocellular carcinoma (HCC) may develop in the natural course of the disease $(1,2)$. Approximately 70-90\% of the cases where HCC develops have bases of chronic liver disease and cirrhosis, while metabolic disorders such as diabetes mellitus (DM) and obesity also play a role in development of HCC $(3,4)$. As known, type $2 \mathrm{DM}$ is a metabolic disease that is usually characterized by hyperglycemia, hyperinsulinemia and

Corresponding Author:-Yasin Ozturk.

Address:-Department of Internal Medicine, ZBEU, Turkey. 
insulin resistance, and it was reported to be associated with increased risk of some cancers: breast, endometrial, kidney, bladder and colorectal $(5,6)$. The role played by DM in the carcinogenesis of HCC is not yet completely clear. In addition to this, it is proposed that hyperglycemia, hyperinsulinemia, insulin resistance and increased IGF-1 activation are effective in the pathophysiology of HCC development by their strong mitogenic and anti-apoptotic effects (7).

In a large cross-sectional study of healthy men and women, the prevalence of DM was found as $8.7 \%$ and $3.8 \%$ respectively in $\mathrm{HCV}$ and $\mathrm{HBV}$ cases (8). Villar et al. found a high $\mathrm{HCV}(2.42 \%)$ and a low $\mathrm{HBV}(0.55 \%)$ prevalence in DM patients (9). The relationship between HBV infections and DM is still under debate. There are several studies that reported high DM prevalence in people who were HBsAg $(+)$, hovewer some others reported the opposite $(10,11)$. Moreover, comorbidity of HCV infections with DM is a well-known issue. Although, there is still ongoing debate about whether HCV infections are an additional risk factor for type 2 DM or they are comorbid infections (12).

In this study, we aimed to assess the potential relationship between chronic hepatitis $\mathrm{C}$ and $\mathrm{B}$ infections in the monitoring of HCC patients who received treatment and comorbidity with DM.

\section{Material and methods:-}

A total of 51 consecutive patients with viral hepatitis-associated HCC in the age group of 35-90 years, who were admitted to the gastroenterology clinic of Bulent Ecevit University Medical Faculty between January 2012 and December 2018, were enrolled in this study. Patients with advanced heart failure, kidney failure, obstructive pulmonary disease, secondary diabetes or severe anemia were excluded. All patients in this study were diagnosed by histology or based on typical imaging findings with increased serum AFP concentrations $(>400 \mu \mathrm{g} / \mathrm{L})$. The Barcelona-Clinic Liver Cancer (BCLC) criteria were used for staging the patients with HCC (13).

Chronic hepatitis $\mathrm{C}$ and $\mathrm{B}$ diagnosis was made by a combination of serological, biochemical, virologic and histological markers according to the AASLD Guidelines for Treatment of CHC and CHB (14, 15). For all these patients, HBsAg and anti-HCV were studied by using the ELISA (Enzyme-Linked Immuno Sorbent Assay; Abbott labr.) method. In the serum samples that were found positive for Anti-HCV, HCV-RNA was investigated by using the method of reverse-transcriptase polymerase chain reaction (RT-PCR). Moreover, in the serum samples collected from the patients, levels of transaminases [alanine aminotransferase (ALT), aspartate aminotransferase (AST)], hemoglobin A1c (HbA1c) and routine biochemical tests were examined. The watients were diagnosed with Type 2 DM according to the American Diabetes Association (ADA) criteria (16). Data including a baseline evaluation including a detailed medical history, typical physical examination and blood tests of patients were collected from the hospital information system retrospectively. The patients were categorized based on age, sex, diabetes presence and types of hepatitis.

The study protocol conformed to the ethical guidelines of the 2013 Declaration of Helsinki as reflected in a priori approval by our institution's human research committee.

\section{Statistical Analysis:-}

Statistical analyses were performed using the Statistical Package for the Social Sciences (SPSS, Version 13.0). Categorical variables are given with frequency and percent, numerical variables are given with median, minimum and maximum values. Shapiro-Wilk test is used for normality tests. For nonparametric variables, Mann Whitney U test used for two group comparions and Kruskal Wallis test used for 3 or more group comparisons. For all statistical analysis with p value under 0,05 is assumed as there is a statistical significance.

\section{Results:-}

The mean age of $51 \mathrm{HCC}$ patients (Female/Male: 12/39) was $69.98 \pm 11.92$ years. Thirty three $(64.7 \%)$ patients had HBV, and $18(35.3 \%)$ had HCV. Ten of the 18 chronic HCV patients (55.6\%) and only 11 of the 33 chronic HBV patients $(33.3 \%)$ that diagnoses of Type $2 \mathrm{DM}(\mathrm{p}=0.107)$. In the comparison of the HCV and HBV groups, there was no significant difference in terms of their plasma glucose and $\mathrm{HbA} 1 \mathrm{C}(\mathrm{p}=0.478$ and $\mathrm{p}=0.261$, respectively). The main characteristics of this group are shown in Table 1. 
Table 1:-Demographics and clinical features of viral hepatitis B and C associated with HCC.

\begin{tabular}{|l|c|c|c|}
\hline \multirow{2}{*}{ Characteristics } & HBV $(+)$ & HCV $(+)$ & $\mathrm{p}$ \\
\cline { 2 - 4 } & $\mathrm{n}=33$ & $\mathrm{n}=18$ & 0.091 \\
\hline Age $(\mathrm{y})$, mean $\pm \mathrm{sd}$ & $68.54 \pm 11.86$ & $72.61 \pm 11.90$ & 0.601 \\
\hline Sex \%(M/F) & $26(78.8) / 7(21.2)$ & $13(72.2) / 5(27.8)$ & 0.261 \\
\hline HbA1C & $6.27 \pm 1.87$ & $6.78 \pm 1.46$ & 0.478 \\
\hline Glucoz & $132.36 \pm 65.99$ & $128.55 \pm 37.56$ & 0.107 \\
\hline Presence of DM \% & $11(33.3)$ & $10(55.6)$ & \\
\hline HBV : Hepatitis B virüs, HCV : Hepatitis C virus,, HCC: Hepatocellular carcinoma \\
\hline
\end{tabular}

When the patients were divided into groups based on the presence of DM, among the $21 \mathrm{DM}$ patients, 11 were positive for $\mathrm{HBsAg}(52.4 \%)$, and 10 were positive for anti-HCV (47.6\%). There was no significant difference between the groups in terms of the presence of chronic HCV and HBV ( $\mathrm{p}=0.127)$ as shown in Table 2.

Table 2 :- The characteristics of HCC patients with/witout diabetes mellitus.

\begin{tabular}{|c|c|c|c|}
\hline \multirow[t]{2}{*}{ Variables } & Diabetic HCC & Non-diabetic HCC & $\mathrm{p}$ \\
\hline & $\mathrm{n}=21$ & $\mathrm{n}=30$ & \\
\hline Age $(y)$, mean \pm sd & $71.28 \pm 9.44$ & $69.06 \pm 13.46$ & 0.737 \\
\hline $\mathrm{Sex}, \mathrm{M} / \mathrm{F}(\%)$ & $16(76.2) / 5(23.8)<$ & $23(76.7) / 7(23.3)$ & 0.969 \\
\hline Platelet (X $1000 / \mathrm{mm} 3$ ) & $131(14-246)$ & $154(18-433)$ & 0.421 \\
\hline $\mathrm{Hb}(\mathrm{g} / \mathrm{dL})$ & $10.02 \pm 3.02$ & $11.63 \pm 2.12$ & 0.050 \\
\hline INR & $1.28(0.9-2.2)$ & $1.44(0.9-3.9)$ & 0.360 \\
\hline Total biliburin (mg / dL) & $3.32(0.3-23.3)$ & $4.18(0.3-33.3)$ & 0.957 \\
\hline Albumin $(\mathrm{g} / \mathrm{dL})$ & $3(1.7-4.4)$ & $3.05(1.7-4.7)$ & 0.890 \\
\hline AFP (ng /mL) median(min-max) & $1070 \pm 1161.2$ & $1064 \pm 1230.1$ & 0.607 \\
\hline \multicolumn{4}{|l|}{ Underlying liver disease } \\
\hline HBV & $11(52.4)$ & $22(73.3)$ & 0.127 \\
\hline $\mathrm{HCV}$ & $10(47.6)$ & $8(26.7)$ & 0.127 \\
\hline \multicolumn{4}{|l|}{ Treatment } \\
\hline Tace & 5 & 9 & \\
\hline $\mathrm{Rf}$ & 2 & 1 & \\
\hline Surgical & 2 & 4 & \\
\hline $\mathrm{Kt}$ & 12 & 16 & \\
\hline Recurrence & - & 3 & \\
\hline
\end{tabular}

Abbreviations: Hb: Hemoglobin, AFP: Alpha fetoprotein, HBV: Hepatitis B virüs, HCV: Hepatitis C virus, INR: İnternational normalized ratio, HCC: Hepatocellular carcinoma

According to BCLC staging, the DM prevalence rates in the A $(n=10), B(n=11), C(n=24)$ and D ( $n=6)$ patients were found respectively as $40 \%, 45.5 \%, 50 \%$ and $0 \%$. Although an increase in the DM rates was observed based on the BCLC stages, diabetes was not found in patients at terminal stage D. The persentages of presence of DM are shown in figure 1.

In a total of 51 primary HCC patients who were included in the study, 27.5\% were receiving transarterial chemoembolization (TACE), 5.9\% were receiving radiofrequency (RF) ablation, $11.8 \%$ received surgical resection, and 54.9\% received only chemotherapy (CT) treatment. Relapse developed in 3 patients after surgery. No patients who developed relapsed HCC had DM. The distribution of treatmet options applied to HCC patients are shown in figure 2. 


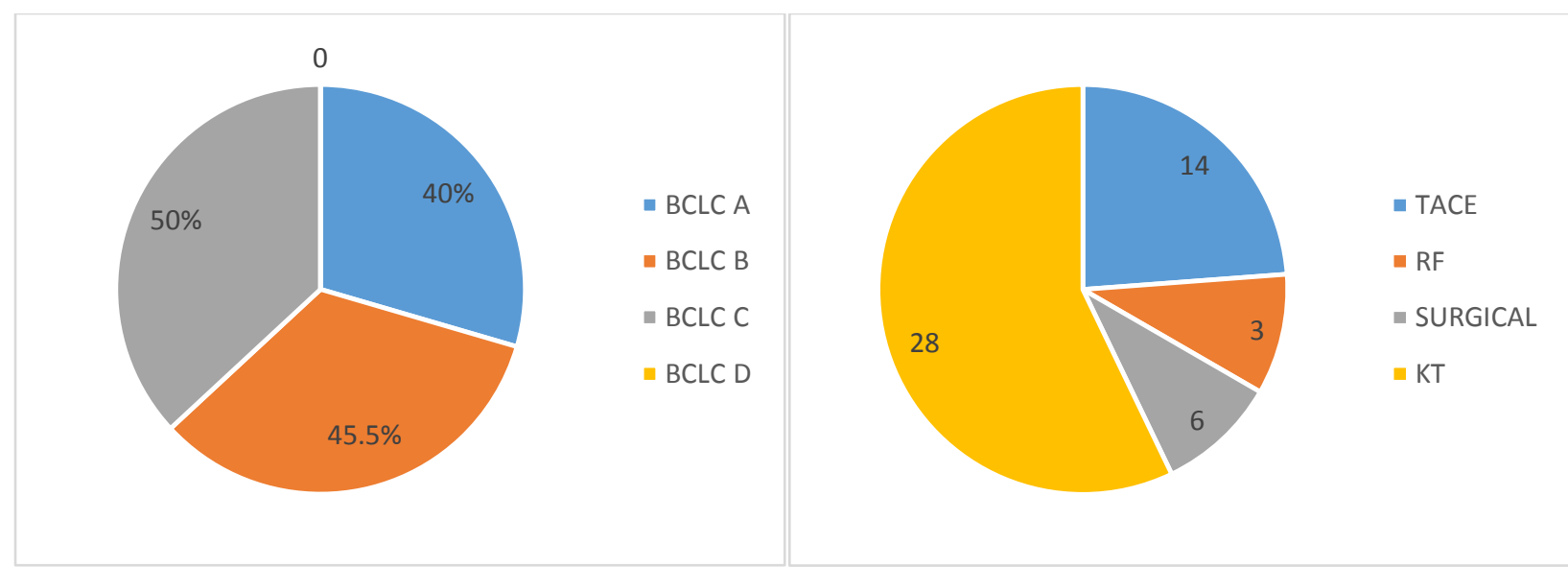

Figure 1:-Prevalence of Diabetes Mellitus in BCLC stages. Figure 2:-The Treatment options of HCC applied to

\section{Discussion:-}

patients

DM has been reported in many studies as a risk factor for liver cancer (7). As known, fibrosis caused by chronic $\mathrm{HCV}$ infection becomes more noticeable in the presence of diabetes (17). In animal models, it was demonstrated that insulin stimulated colon carcinogenesis (promoter effect), and it played a role like the growth factor of many tumors in in vitro environments (18). It is known that, in cases with HCV infections, high insulin levels may increase chronic inflammation and oxidative stress, lead to death o hepatocytes, and consequently, cause increased regeneration signals in residue hepatocytes. In fact, the gene expression profile in the liver varies in diabetic cases towards a fibrogenic, angiogenic and tumorigenic phenotype (19). Moreover, based on these data, Fong et al. reported that diabetes presence may increase the speed of primary liver cancer formation by increasing fibrogenesis in HCV-infected cases (20). Similarly, a meta-analysis revealed that Type 2 DM increased the risk of HCC also in chronic viral hepatitis B patients (21).

While the most frequently encountered etiological factor in HCC cases is chronic viral hepatitis B by over 50\%, chronic hepatitis $\mathrm{C}$ is found to be responsible by the rate of $25 \%$ (22). In the results of our study, in agreement with the literature, $35.3 \%$ of the HCC patients were positive for anti-HCV, while $64.7 \%$ were positive for HBsAg. In contrast, Tanaka et al. conducted a study on 91 HCC patients and reported the positivity rates for anti-HCV and HBsAg as respectively $51 \%$ and $21 \%$ (23).

In our study, the general DM presence in the HCC patients was $41.2 \%$. This rate for the HBV and HCV patients was respectively $33.3 \%$ and $55.6 \%$. The difference between the groups was statistically significant. Although the presence of diabetes has very little synergistic effect in cases infected with HBV, it seems more likely that this effect is very strongly synergistic in HCV-infected cases. Again, in our study, when the patients were divided into groups as those with DM and those without, there was no significant difference between the groups in terms of their HBV and $\mathrm{HCV}$ rates. As known, liver carcinogenesis associated with HBV and HCV includes different mechanisms (24). The HBV virus integrates its DNA into the cell genome, while there is no such situation in the case of the HCV factor. Thus, synergism in carcinogenesis may be expected in the case of presence of HCV and diabetes rather than HBV and diabetes mellitus.

Su et al. investigated the effects of DM on survival in 3,182 HCC patients and used the BCLC staging criteria (25). They reported that diabetic patients had a poorer prognosis. In their study, the prevalence of DM for the BCLC stages of $\mathrm{O}, \mathrm{A}, \mathrm{B}, \mathrm{C}$ and $\mathrm{D}$ was found respectively as $22.0 \%, 24.1 \%, 21.9 \%, 27.2 \%$ and $27.1 \%$. There was a rising trend in DM prevalence by advancing stages of the disease. In our patient group, the DM rates in the BCLC stages of A, B and C were respectively $40 \%, 45.5 \%$ and $50 \%$. These findings supported the hypothesis that DM is related to the progression of HCC.

Komura et al. investigated the effects of diabetes on postoperative relapse in cases where resection was applied due to primary liver cancer. In their study that included $90 \mathrm{HCC}$ patients, the total survival rates in the diabetic group after surgical treatment in the 1st, 2nd, 3rd, 4th and 5th years were respectively $100 \%, 88.9 \%, 75 \%, 63.6 \%$ and $45.5 \%$, while these rates in a group of 60 individuals without diabetes were respectively $100 \%, 98 \%, 88.9 \%, 85.7 \%$ 
and $76.3 \%$. Consequently, in their report, they proposed that insulin usage and Child score B are important in terms of postoperative relapse in HCV-related primary liver cancer cases. The authors also provided a speculative suggestion that close blood sugar management in these cases may reduce relapse (26). In contrast, Huo et al. investigated the effects of presence of diabetes on postoperative relapse similarly on HCV-related cases, and they reported no significant effects of diabetes (27). As our study was a retrospective study and included a small number of patients, it does not seem to be adequate to be able to provide strong statistical evidence.

\section{Conclusion:-}

Consequently, it was revealed in experimental animal studies and in vitro studies that the effects of glucose anomalies may make tumor formation easier in the liver, colon and rectum or several other organ systems. The clinical outcomes of this effect, especially those associated with its relationship with increase postoperative relapse in cases of liver cancer, have not yet been clarified. It does not yet seem likely to argue that close monitoring of blood sugar may reduce disease progression in chronic viral hepatitis patients.

\section{Acknowledgments:-}

The authors would like to thank the patients who willingly participated in the study.

\section{References:-}

1. McKeating C, Cadden I, McDougall N, Jessop L, Quah S, Lavelle M, et al. Progression from acute to chronic hepatitis B is more common in older adults. The Ulster medical journal. 2018;87(3):177.

2. Chen SL, Morgan TR. The natural history of hepatitis $\mathrm{C}$ virus (HCV) infection. International journal of medical sciences. 2006;3(2):47.

3. Sanyal AJ, Yoon SK, Lencioni R. The etiology of hepatocellular carcinoma and consequences for treatment. The oncologist. 2010;15(Supplement 4):14-22.

4. Ghouri YA, Mian I, Rowe JH. Review of hepatocellular carcinoma: Epidemiology, etiology, and carcinogenesis. Journal of carcinogenesis. 2017;16.

5. McCulloch DK, Robertson RP. Risk factors for type 2 diabetes mellitus. UpToDate Disponible en: URL: http://www uptodate com/contents/risk-factors-for-type-2-diabetes-mellitus [último acceso: 23 de febrero de 2015]. 2016.

6. Giovannucci E, Harlan DM, Archer MC, Bergenstal RM, Gapstur SM, Habel LA, et al. Diabetes and cancer: a consensus report. CA: a cancer journal for clinicians. 2010;60(4):207-21.

7. Singh MK, Das BK, Choudhary S, Gupta D, Patil UK. Diabetes and hepatocellular carcinoma: A pathophysiological link and pharmacological management. Biomedicine \& Pharmacotherapy. 2018;106:9911002.

8. Hong YS, Chang Y, Ryu S, Cainzos-Achirica M, Kwon M-J, Zhang Y, et al. Hepatitis B and C virus infection and diabetes mellitus: A cohort study. Scientific reports. 2017;7(1):4606.

9. Villar LM, Geloneze B, Vasques ACJ, Pires MLE, Miguel JC, da Silva EF, et al. Prevalence of hepatitis B and hepatitis C among diabetes mellitus type 2 individuals. PloS one. 2019;14(2):e0211193.

10. Huang ZS, Huang TS, Wu TH, Chen MF, Hsu CS, Kao JH. Asymptomatic chronic hepatitis B virus infection does not increase the risk of diabetes mellitus: a ten-year observation. Journal of gastroenterology and hepatology. 2010;25(8):1420-5.

11. Spradling P, Simons B, Narayanan M, Xing J, Homan C, Bulkow L, et al. Incidence of diabetes mellitus in a population-based cohort of persons with chronic hepatitis B virus infection. Journal of viral hepatitis. 2013;20(7):510-3.

12. Hammerstad SS, Grock SF, Lee HJ, Hasham A, Sundaram N, Tomer Y. Diabetes and hepatitis C: a two-way association. Frontiers in endocrinology. 2015;6:134.

13. Llovet JM, Fuster J, Bruix J. The Barcelona approach: diagnosis, staging, and treatment of hepatocellular carcinoma. Liver transplantation. 2004;10(S2):S115-S20.

14. Chung RT, Ghany MG, Kim AY, Marks KM, Naggie S, Vargas HE, et al. Hepatitis C guidance 2018 update: AASLD-IDSA recommendations for testing, managing, and treating hepatitis $\mathrm{C}$ virus infection. Clinical Infectious Diseases. 2018.

15. Terrault NA, Lok AS, McMahon BJ, Chang KM, Hwang JP, Jonas MM, et al. Update on prevention, diagnosis, and treatment of chronic hepatitis B: AASLD 2018 hepatitis B guidance. Hepatology. 2018;67(4):1560-99.

16. Association AD. 2. Classification and diagnosis of diabetes: standards of medical care in diabetes-2018. Diabetes care. 2018;41(Supplement 1):S13-S27. 
17. Hum J, Jou JH. The link between hepatitis $\mathrm{C}$ virus and diabetes mellitus: Improvement in insulin resistance after eradication of hepatitis $C$ virus. Clinical liver disease. 2018;11(3):73.

18. Giovannucci E. Nutrition, insulin, insulin-like growth factors and cancer. Hormone and Metabolic Research. 2003;35(11/12):694-704.

19. Takamura T, Sakurai M, Ota T, Ando H, Honda M, Kaneko S. Genes for systemic vascular complications are differentially expressed in the livers of type 2 diabetic patients. Diabetologia. 2004;47(4):638-47.

20. Fong DG, Nehra V, Lindor KD, Buchman AL. Metabolic and nutritional considerations in nonalcoholic fatty liver. Hepatology. 2000;32(1):3-10.

21. Tan Y, Wei S, Zhang W, Yang J, Yang J, Yan L. Type 2 diabetes mellitus increases the risk of hepatocellular carcinoma in subjects with chronic hepatitis B virus infection: a meta-analysis and systematic review. Cancer management and research. 2019;11:705.

22. Schwartz JM, Carithers R. Epidemiology and etiologic associations of hepatocellular carcinoma. Wolters Kluwer UpToDate website. www. upto-date. com/contents/epidemiology ...; 2013.

23. Tanaka K, Hirohata T, Koga S, Sugimachi K, Kanematsu T, Ohryohji F, et al. Hepatitis C and hepatitis B in the etiology of hepatocellular carcinoma in the Japanese population. Cancer research. 1991;51(11):2842-7.

24. Fung J, Lai C-L, Yuen M-F. Hepatitis B and C virus-related carcinogenesis. Clinical microbiology and infection. 2009;15(11):964-70.

25. Su Y-W, Liu P-H, Hsu C-Y, Lee Y-H, Hsia C-Y, Ho S-Y, et al. Prognostic impact of diabetes mellitus on hepatocellular carcinoma: Special emphasis from the BCLC perspective. PloS one. 2017;12(3):e0174333.

26. Komura T, Mizukoshi E, Kita Y, Sakurai M, Takata Y, Arai K, et al. Impact of diabetes on recurrence of hepatocellular carcinoma after surgical treatment in patients with viral hepatitis. The American journal of gastroenterology. 2007;102(9):1939.

27. Huo T-I, Wu J-C, Lui W-Y, Lee P-C, Huang Y-H, Chau G-Y, et al. Diabetes mellitus is a recurrenceindependent risk factor in patients with hepatitis B virus-related hepatocellular carcinoma undergoing resection. European journal of gastroenterology \& hepatology. 2003;15(11):1203-8. 